A) Check for updates

Cite this: Food Funct., 2018, 9, 1578

\section{Revalorization of wild Asparagus stipularis Forssk. as a traditional vegetable with nutritional and functional properties}

\author{
Khaoula Adouni, ${ }^{\text {a,b,c }}$ Hassiba Chahdoura, ${ }^{a}$ Habib Mosbah, ${ }^{a}$ \\ Celestino Santos-Buelga, (D) *b Ana M. González-Paramás, ${ }^{b}$ María Ciudad-Mulero, ${ }^{c}$ \\ Ângela Fernandes, ${ }^{d}$ Ricardo C. Calhelha, ${ }^{d}$ Patricia Morales, (D) *c Guido Flamini, ${ }^{e, f}$ \\ Isabel C. F. R. Ferreira (iD d and Lotfi Achour ${ }^{a}$
}

\begin{abstract}
The nutritional values and phytochemical composition of young shoots of wild Asparagus stipularis Forssk. from Tunisia were determined in this study. The antioxidant (tested by four different in vitro assays) and antiproliferative properties (against human tumour cell lines) of aqueous and hydroalcoholic extracts of the young shoots were also investigated. The obtained results indicated that the young shoots are a potential source of valuable nutrients and dietary fiber, and their hydroalcoholic extract showed marked antioxidant and antiproliferative activities in all tested assays. The major phenolic compound, characterized by using a high-performance liquid chromatograph coupled with diode-array and mass spectrometer detectors, in both extracts was diferuloyl glycerol. Our results reinforce the interest in recovering the traditional culinary uses of this wild plant, with potential functional properties, which can be included in the modern diet as an alternative to the variety of vegetables normally used.
\end{abstract}

Received 26th October 2017, Accepted 20th January 2018 DOI: $10.1039 / \mathrm{c} 7 \mathrm{fo} 01687 \mathrm{e}$ rsc.li/food-function properties of this genus have been described in both European and Asian cultures. ${ }^{10,11}$

Young shoots of wild Asparagus stipularis are traditionally consumed by rural populations of Cyprus, Rhodes, Greece, Egypt, Algeria and Tunisia. ${ }^{12}$ In addition, the infusion of their tuberous roots has been reported to alleviate headache, prevent renal stone formation and cure syphilis. The decoction of the whole plant is used to relieve stomach ache and promote appetite. ${ }^{13}$ Although the phytochemistry and phytotherapy of cultivated Asparagus officinalis and wild Asparagus acutifolius are relatively well known, there have been very few published data on the biochemical composition and biological properties of $A$. stipularis young shoots.

Wild edible food sources, particularly wild vegetables, have fallen into neglect since their traditional uses are being lost throughout generations. The revalorization of these wild vegetables as potential sources of functional food ingredients and/or including their consumption in modern diets could contribute to the preservation of their traditional knowledge and culinary uses, as well as to improve the biodiversity and rural sustainability of the collection areas. Thus, the aim of this study was to characterize the nutritional value and bioactive compounds of $A$. stipularis young shoots, paying special attention to the functional properties (antioxidant and antiproliferative activities) of the aqueous and hydroalcoholic extracts. 


\section{Materials and methods}

\subsection{Plant material}

Wild Asparagus stipularis Forssk. young shoots were collected in January (2015) from the cliff of Monastir (Tunisia). The plant was dried by active ventilation at $37^{\circ} \mathrm{C}$. The dried young shoots were ground in an ultra-centrifugal mill ZM 200 (Retsch, Haan, Germany).

\subsection{Standards and reagents}

All organic solvents were HPLC grade. HMDS, TMCS, pyridine, 2,2-diphenyl-1-picrylhydrazyl (DPPH), and 2,2'-azinobis(3-ethylbenzothiazoline-6-sulphonic acid) diammonium salt (ABTS) were purchased from Sigma-Aldrich Co. (St Louis, MO, USA). The metals (Fe, $\mathrm{Cu}, \mathrm{Mn}$ and $\mathrm{Zn}$ ) were purchased from Merck (Darmstadt, Germany). The standards of organic acids (citric acid, malic acid and oxalic acid) and tocopherols ( $\alpha-, \beta-, \gamma^{-}$, and $\delta$-isoforms) were purchased from sigma. The phenolic compound standards were obtained from Extrasynthese (Genay, France).

\subsection{Nutritional value}

2.3.1. Proximate composition. Moisture, protein, fat and ash were determined following the AOAC procedures. ${ }^{14}$ The moisture content was determined using an air oven. The crude fat was extracted using a Soxhlet apparatus. The nitrogen content was estimated by using the micro-Kjeldahl method and the factor 6.25 was used to convert the nitrogen content to protein content. The ash content was determined by incineration at $550 \pm 15^{\circ} \mathrm{C}$.

2.3.2. Carbohydrates (soluble sugars, oligosaccharides and polyols). The extraction, identification and characterization of individual soluble sugars were done by GS-MS according to the method described by Mechri et al. ${ }^{15}$ The quantification of each compound was performed using the internal standard calculation method. The analyses were performed in triplicate. The values are expressed as mg per $100 \mathrm{~g}$ fw.

2.3.3. Total, soluble and insoluble dietary fiber. The fiber content was determined according to the enzymatic-gravimetric methods (993.19 and 991.42) as previously described. ${ }^{16}$ Powdered spear was subjected to sequential enzymatic digestion by $\alpha$-amylase, protease and amyloglucosidase. Vacuum filtration was used to separate the soluble and insoluble fractions. The residue of filtration was dried at $100{ }^{\circ} \mathrm{C}$ and the ash and protein contents were determined. The contents of total dietary fibre as well as soluble and insoluble dietary fibre fractions are expressed as $\mathrm{g}$ per $100 \mathrm{~g}$ fw sample.

2.3.4. Energy. Energy was calculated according to the following equation:

$$
\begin{aligned}
& \text { Energy (kcal per } 100 \mathrm{~g} \text { fresh weight }) \\
& \quad=\left[4 \times\left(g_{\text {protein }}+g_{\text {soluble sugar }}\right)+2 \times\left(g_{\text {fiber }}\right)+9 \times\left(g_{\text {fat }}\right)\right]
\end{aligned}
$$

2.3.5. Mineral elements. The method 930.05 of the $\mathrm{AOAC}^{14}$ procedures was used. $300 \mathrm{mg}$ of powdered young shoots was subjected to dry-ash mineralization in an oven at $550 \pm 15^{\circ} \mathrm{C}$. The residue was digested with $\mathrm{HCl}(50 \% \mathrm{v} / \mathrm{v})$ and $\mathrm{HNO}_{3}(50 \%$ $\mathrm{v} / \mathrm{v})$. Zinc $(\mathrm{Zn})$, iron $(\mathrm{Fe})$, copper $(\mathrm{Cu})$ and magnesium $(\mathrm{Mn})$ were quantified by atomic absorption spectroscopy (AAS) using an Analyst 200 PerkinElmer equipment (PerkinElmer, Waltham, MA, USA). An additional 1/10 (v/v) dilution of the sample fraction and standards was performed for macroelement determination: for $\mathrm{Ca}$ and $\mathrm{Mg}$ analysis in 1.16\% $\mathrm{La}_{2} \mathrm{O}_{3} / \mathrm{HCl}$ (leading to $\mathrm{LaCl}_{2}$ ) and for $\mathrm{Na}$ and $\mathrm{K}$ analysis in $0.2 \% \mathrm{CsCl}$. The results are expressed in $\mathrm{mg}$ per $100 \mathrm{~g}$ fw.

2.3.6. Fatty acid composition. Fatty acids were determined by using the gas-liquid chromatographic method ${ }^{17}$ with slight modifications. Fatty acids (obtained after Soxhlet extraction) were treated with methanolic $\mathrm{KOH}$ to obtain fatty acid methyl esters (FAMEs). FAMEs were identified by comparison of their retention time with the pure standards analyzed under the same conditions. All fatty acid peak areas were calculated using the HP ChemStation software and recorded as peak area percentages. The results are expressed as relative percentage.

\subsection{Bioactive compounds}

2.4.1. Organic acids. Organic acids were determined using ultra-fast liquid chromatography (UFLC) following a procedure previously optimized and described by Dias et $a l^{18}$ The organic acids found were quantified by comparison of the area of their peaks recorded with the calibration curves obtained from the commercial standards of each compound. The results are expressed in $\mathrm{g}$ per $100 \mathrm{~g}$ of fresh weight (fw).

2.4.2. Tocopherols. Tocopherols were determined following a procedure previously described by Dias et al. ${ }^{18}$ The compounds were identified by chromatographic comparison with authentic standards. The quantification was based on the fluorescence signal response of each standard, using the internal standard method. The results are expressed in mg per $100 \mathrm{~g}$ of fresh weight (fw).

2.4.3. Volatile compound analysis. Solid-phase microextraction (SPME) was performed with further analysis by GC-MS as previously described. ${ }^{19}$ The retention times served for the identification of constituents comparing their linear retention indices (LRI) on computer matching against the library mass spectra, and the MS literature data.

\subsubsection{Phenolic compounds}

Preparation of aqueous and hydroalcoholic extracts. The extracts were prepared as previously described. ${ }^{13}$ For hydroalcoholic extraction, $1 \mathrm{~g}$ of powdered young shoots was stirred with $30 \mathrm{~mL}$ of a mixture of methanol: water $(80: 20, \mathrm{v} / \mathrm{v})$ at $25^{\circ} \mathrm{C}$ and $150 \mathrm{rpm}$ for $1 \mathrm{~h}$. The extract was then filtered and the residue was further extracted with a $30 \mathrm{~mL}$ portion of the hydroalcoholic mixture. The combined supernatants were then evaporated and lyophilized. For aqueous preparation (infusion), $1 \mathrm{~g}$ of powdered young shoots was added to $200 \mathrm{ml}$ of boiled water and allowed to stabilize at room temperature. The solution was then filtered, frozen and lyophilized.

HPLC-DAD-ESI/MS analyses for individual phenolic compounds. The analyses of individual phenolic compounds were carried out on the hydroalcoholic and infusion extracts by HPLC using double online detection by diode array spectrophotometry and mass spectrometry (MS). A Hewlett-Packard 
1100 chromatograph (Hewlett-Packard 1100, Agilent Technologies, Santa Clara, CA, USA) provided with a quaternary pump and a diode array detector (DAD) coupled with an HP ChemStation (rev. A.05.04) data-processing station was used. The system was connected via the cell outlet to an MS detector API 3200 Qtrap (Applied Biosystems, Darmstadt, Germany) that was controlled by the Analyst 5.1 software. The separation was achieved on an Agilent Poroshell 120 EC-C18, $2.7 \mu \mathrm{m}(4.6 \times 150 \mathrm{~mm})$ column thermostated at $35^{\circ} \mathrm{C}$. The solvents were (A) $0.1 \%$ formic acid and (B) acetonitrile. The elution gradient established was isocratic 15\% B for 5 min, 15-20\% B over $5 \mathrm{~min}, 20-35 \%$ B over $10 \mathrm{~min}, 35-50 \%$ B over $10 \mathrm{~min}, 50-60 \%$ B over $5 \mathrm{~min}$, isocratic $60 \% \mathrm{~B}$ for $5 \mathrm{~min}$ and re-equilibration of the column to the initial solvent conditions. The flow rate was $0.5 \mathrm{~mL} \mathrm{~min}^{-1}$. UV detection was performed using 280, 330 and $370 \mathrm{~nm}$ as the preferred wavelengths. MS spectra were recorded in the negative ion mode between $\mathrm{m} / \mathrm{z}$ 100 and $m / z$ 1500. Zero grade air served as the nebulizer gas (30 psi) and as the turbo gas $\left(400{ }^{\circ} \mathrm{C}\right)$ for solvent drying (40 psi). Nitrogen served as the curtain (20 psi) and collision gas (medium). Both quadrupoles were set at unit resolution and EMS and EPI analyses were also performed. The EMS parameters were: ion spray voltage $4500 \mathrm{~V}, \mathrm{DP}-50 \mathrm{~V}, \mathrm{EP}-6 \mathrm{~V}$, $\mathrm{CE}-10 \mathrm{~V}$ and cell exit potential (CXP) $-3 \mathrm{~V}$, whereas the EPI settings were: DP $-50 \mathrm{~V}, \mathrm{EP}-6 \mathrm{~V}, \mathrm{CE}-25 \mathrm{~V}$ and CES $0 \mathrm{~V}$. The individual phenolic compounds were tentatively identified by comparing their UV and mass spectra with those reported in the literature, as well as with standards when available. For quantitative analysis, calibration curves were prepared from caffeic acid (for hydroxycinnamoyl derivatives) and kaempferol-3-O-glucoside (for flavonoids). The results are expressed in $\mathrm{mg}$ per $100 \mathrm{~g}$ of dry weight $(\mathrm{dw})$.

\subsection{Bioactive properties}

2.5.1. Evaluation of the antioxidant activity. DPPH radicalscavenging activity, ABTS radical cation scavenging activity and ferric reducing antioxidant power (FRAP) were determined. ${ }^{19}$ Moreovers, Lipid peroxidation inhibion was evaluated using assay thiobarbituric acid reactive substances (TBARS). ${ }^{20}$ The results of the determination of the above antioxidant activities are expressed in $\mathrm{EC}_{50}$ values, i.e. sample concentration providing $50 \%$ of antioxidant activity or 0.5 of absorbance in the reducing power assay. Regarding the DNA nicking assay, ${ }^{21}$ a volume of $5 \mu \mathrm{L}$ of each extract at a concentration of $2 \mathrm{mg} \mathrm{mL}$ was added to $2 \mu \mathrm{L}$ of pGEM®-Tplasmid DNA ( $0.5 \mu \mathrm{g}$ per well). The mixtures were then kept for $10 \mathrm{~min}$ at room temperature, followed by the addition of $10 \mu \mathrm{L}$ of Fenton's reagent $(3 \mathrm{mM}$ $\mathrm{H}_{2} \mathrm{O}_{2}, 50 \mu \mathrm{M}$ L-ascorbic acid and $80 \mu \mathrm{M} \mathrm{FeCl}$ ). The mixtures were incubated for $5 \mathrm{~min}$ at $37^{\circ} \mathrm{C}$ and the DNA was then analyzed by $1 \%(\mathrm{w} / \mathrm{v})$ agarose gel electrophoresis and visualized under UV light.

\subsubsection{Antiproliferative properties}

Cytotoxicity assays. All the assays were carried out in triplicate and the results are expressed as $\mathrm{GI}_{50}$ values in $\mu \mathrm{g} \mathrm{mL}^{-1}$ (sample concentration that inhibited $50 \%$ of the net cell growth). Ellipticine was used as the positive control in the assays.

Evaluation of cytotoxicity in human tumor cell lines. Four human tumor cell lines were used: MCF-7 (breast adenocarcinoma), NCI-H460 (non-small cell lung cancer), HeLa (cervical carcinoma) and HepG2 (hepatocellular carcinoma), as previously described by Dias et al. ${ }^{18}$

Evaluation of cytotoxicity in a porcine liver primary cell culture. For the evaluation of the cytotoxicity in non-tumor cells, a cell culture was prepared from a freshly harvested porcine liver (PLP2) according to the procedure established by Dias et al. ${ }^{18}$

\subsection{Statistical analysis}

All the assays were carried out in triplicate. The results are expressed as mean values \pm standard deviation (SD), being analysed using a Student's $t$-test, with $\alpha=0.05$.

\section{Results and discussion}

\subsection{Nutritional value}

The results of the nutritional composition (expressed on a fresh weight basis) are shown in Table 1 . The young shoots revealed high moisture and dietary fiber content (82.38 and $11.88 \mathrm{~g}$ per $100 \mathrm{~g}$, respectively), whereas the other macronutrients were found in lower amounts $(0.82,1.19$ and $3.64 \mathrm{~g}$ per $100 \mathrm{~g}$ for ash, proteins and lipids, respectively).

It is well known that a daily intake of $7 \mathrm{~g}$ of plant dietary fiber is considered enough to significantly decrease the menace of cardiovascular and coronary heart diseases. ${ }^{7}$ In this sense, the consumption of $100 \mathrm{~g}$ of fresh young shoots of A. spitularis would cover this daily recommended dose. Thus, wild asparagus can be considered an interesting source of dietary fiber and could be added to other food products to improve fiber intake.

It can be noted that the value of proteins is similar to that reported in cultivated asparagus (Asparagus officinalis) young shoots, but less than that reported for wild asparagus (Asparagus acutifolius) young shoots. The total lipids amount is higher than the values reported for both the above species. ${ }^{1}$ The energy value expressed as kcal per $100 \mathrm{~g}$ was 51.57. Comparing our results with those reported for the energy values of selected Mediterranean wild edible plants, A. stipularis young shoots showed a higher value than Anchusa azurea Mill (24 kcal), Apium nodiflorum (L.) Lag. (21 kcal), Asparagus acutifolius (40 kcal) and Beta maritime L. (31 kcal). ${ }^{7}$ The contents of soluble dietary fiber (SDF) and insoluble dietary fiber (IDF) were evaluated in the young shoots, IDF being the main fraction (11.01 g per $100 \mathrm{~g}$ fw; Table 1). Previous studies demonstrated that dietary fiber is able to interfere with enterohepatic bile circulation, decreasing cholesterol and bile acid absorption and causing the depletion of hepatic cholesterol pools. ${ }^{22}$

The micro- and macroelement content, expressed as mg per $100 \mathrm{~g} \mathrm{fw}$, is given in Table 1. For microelements, Mn, $\mathrm{Zn}, \mathrm{Cu}$ and Fe were detected. The Fe content was the highest $(1.47 \mathrm{mg}$ 
Table 1 Proximate composition (g per $100 \mathrm{~g} \mathrm{fw}$ ), microelements (mg per $100 \mathrm{~g} \mathrm{fw}$ ), soluble sugars (g per $100 \mathrm{~g} \mathrm{fw}$ ), dietary fiber (g per $100 \mathrm{~g}$ $\mathrm{fw}$ ), organic acids (g per $100 \mathrm{~g} \mathrm{fw}$ ) and energy value (kcal per $100 \mathrm{~g} \mathrm{fw}$ ) of Asparagus stipularis Forssk. young shoots

Content

Proximate composition ( $\mathrm{g}$ per $\mathbf{1 0}$
Moisture
Crude proteins
Total fat
Total ash
Microelements (mg per $100 \mathrm{~g} \mathbf{f w}$ )
$\mathrm{Fe}$
$\mathrm{Cu}$
$\mathrm{Mn}$
$\mathrm{Zn}$
$\mathrm{Macroelements} \mathrm{(mg} \mathrm{per} \mathbf{1 0 0 g} \mathbf{f w}$ )
$\mathrm{Ca}$
$\mathrm{Mg}$
$\mathrm{Na}$
$\mathrm{K}$

$82.38 \pm 0.35$

$3.64 \pm 0.11$

$1.19 \pm 0.005$

$0.82 \pm 0.05$

$1.47 \pm 0.07$

$0.74 \pm 0.03$

$0.05 \pm 0.002$

$0.78 \pm 0.02$

$137.79 \pm 8.08$

$45.47 \pm 1.17$

$5.00 \pm 0.24$

$197.07 \pm 4.79$

Total soluble sugars ( $g$ per $100 \mathrm{~g}$ fw)

Fructose

Glucose

Sucrose

Galactose

Arabinose

Rhamnose

Raffinose

Inositol

Total dietary fiber ( $\mathrm{g}$ per $100 \mathrm{~g}$ fw)

Soluble dietary fiber

Insoluble dietary fiber

Total organic acids ( $\mathrm{g}$ per $100 \mathrm{~g}$ fw)

Oxalic acid

Malic acid

Citric acid

Energy (kcal per $100 \mathrm{~g}$ fw)
Regarding the macroelements, $\mathrm{Ca}, \mathrm{Mg}, \mathrm{Na}$ and $\mathrm{K}$ were quantified, $\mathrm{K}$ and $\mathrm{Ca}$ being the major macroelements found in young shoots with values of 197.07 and $137.79 \mathrm{mg}$ per 100 $\mathrm{g}$ fw, respectively. In both cases, the obtained results were higher than those reported for A. acutifolius. ${ }^{7}$ The Na content (5.00 $\mathrm{mg}$ per $100 \mathrm{~g} \mathrm{fw}$ ) was much lower than that reported for this wild asparagus (18.5 mg per $100 \mathrm{~g} \mathrm{fw}){ }^{7}$ Moreover, the oxalic acid/Ca ratio was 1.08 (must be lower than 2.5), which means that the consumption of this wild vegetable reduces the bioavailability of dietary $\mathrm{Ca}$ by the formation of an insoluble complex of calcium oxalate. ${ }^{16}$

The concentrations of soluble sugars, namely monosaccharides (mannose, glucose, fructose, galactose, arabinose and rhamnose), sugar alcohols (inositol), disaccharides (sucrose) and oligosaccharides (raffinose) detected in A. stipularis young shoots are given in Table 1 . The analysis revealed that sucrose was the predominant soluble sugar in the investigated sample. Similar results have been reported by Martins et al. ${ }^{2}$ who also detected sucrose as the most abundant sugar in wild green asparagus. Moreover, Martins et $a l^{2}{ }^{2}$ reported that, under normal culture conditions, the content of sucrose was generally higher than the glucose and fructose values. Regarding polyols, inositol was detected in appreciable amounts in the herein studied sample. According to Mechri et al., ${ }^{15}$ polyols may function as scavengers of activated oxygen species which prevent lipid peroxidation and cell damage.

The results for the determination of fatty acid composition, total saturated fatty acids (SFA), monounsaturated fatty acids (MUFA), polyunsaturated fatty acids (PUFA) and the ratios PUFA/SFA and n-6/n-3 are shown in Table 2. Palmitic acid (PA; $16: 0$ ) was the most abundant saturated acid. PA is one of the most common saturated fatty acids found in animals and plants. The World Health Organization claims that the consumption of PA raises the risk of developing cardiovascular diseases. However, French et al. ${ }^{26}$ concluded that PA has no hypercholesterolemic effect if the intake of LA (linoleic acid) is above $4.5 \%$ of energy. The unsaturated fatty acid percentage was higher $(54.67 \%)$ than that of SFA $(45.43 \%)$. Oleic acid (n-9; 18:1) was the main monounsaturated fatty acid (11.62\%), while linoleic acid (n-6; C18:2) and $\alpha$-linolenic acid (n-3; C18:3) were the main PUFA. These results are in agreement with those reported in other wild Asparagus species. ${ }^{3,6}$ The ratios PUFA/ SFA and n-6/n-3 fatty acids were also determined. According to nutritional recommendations, values above 0.45 and lower than 4.0 are highly desirable for PUFA/SFA and n-6/n-3 fatty acid ratios, respectively. ${ }^{3}$ Both criteria are met in $A$. stipularis young shoots (Table 2).

\subsection{Bioactive compounds}

3.2.1. Organic acids. The results for the determination of organic acid contents are presented in Table 1 . The average concentration of total organic acids in the analyzed wild asparagus was $1.93 \mathrm{~g}$ per $100 \mathrm{~g}$ fw. Citric acid was the most abundant $(1.58 \mathrm{~g}$ per $100 \mathrm{~g}$ fw $)$ followed by malic acid $(0.18 \mathrm{~g}$ per $100 \mathrm{~g} \mathrm{fw}$ ) and oxalic acid (0.15 g per $100 \mathrm{~g} \mathrm{fw}$ ). Similarly, Pereira et $a l .{ }^{5}$ described citric acid as the main organic acid in 
Table 2 Main fatty acid composition (relative percentage of total fatty acids) and tocopherols (mg per $100 \mathrm{~g} \mathrm{fw}$ ) evaluated in Asparagus stipularis Forssk. young shoots

\begin{tabular}{lc}
\hline Fatty acid & Fatty acid content (relative percentage) \\
\hline Saturated & \\
C6: 0 & $0.27 \pm 0.075$ \\
C12:0 & $1.45 \pm 0.011$ \\
C14:0 & $0.35 \pm 0.12$ \\
C15:0 & $0.72 \pm 0.06$ \\
C16:0 & $31.09 \pm 0.02$ \\
C17:0 & $0.68 \pm 0.011$ \\
C18:0 & $4.31 \pm 0.011$ \\
C20:0 & $3.13 \pm 0.01$ \\
C22:0 & $0.65 \pm 0.07$ \\
C23:0 & $0.66 \pm 0.02$ \\
C24:0 & $2.12 \pm 0.01$ \\
& \\
Monounsaturated & \\
C16:1 (n-9) & $1.44 \pm 0.0$ \\
C18:1 (n-9) & $11.62 \pm 0.007$ \\
C20:1 (n-9) & $0.75 \pm 0.06$ \\
Polyunsaturated & \\
C18:2 (n-6) & $31.47 \pm 0.009$ \\
C18:3 (n-3) & $8.66 \pm 0.01$ \\
C20:2 (n-6) & $0.73 \pm 0.05$ \\
Total SFA & $\mathbf{4 5 . 4 3} \pm \mathbf{0 . 0 0 4}$ \\
Total MUFA & $\mathbf{1 3 . 8 0} \pm \mathbf{0 . 0 1 2}$ \\
Total PUFA & $\mathbf{4 0 . 8 7} \pm \mathbf{0 . 0 0 2}$ \\
PUFA/SFA & $\mathbf{0 . 8 9} \pm \mathbf{0 . 0 0 5}$ \\
n-6/n-3 & $\mathbf{3 . 7 1} \pm \mathbf{0 . 0 4}$ \\
$\alpha-$ Tocopherol & $0.06 \pm 0.003$ \\
$\gamma$-Tocopherol & $0.07 \pm 0.002$ \\
Total tocopherols & $\mathbf{0 . 1 3} \pm \mathbf{0 . 0 0 1}$ \\
& \\
\hline &
\end{tabular}

the young shoots of other wild asparagus samples (Asparagus acutifolius).

3.2.2. Tocopherols. In the analysed sample, $\alpha$-tocopherol (0.06 $\mathrm{mg}$ per $100 \mathrm{~g} \mathrm{fw})$ and $\gamma$-tocopherol $(0.07 \mathrm{mg}$ per $100 \mathrm{~g} \mathrm{fw})$ were determined (Table 2); the $\delta$ - and $\beta$-isoforms were not detected, opposite to what was reported in other wild asparagus species (A. acutifolius) by Morales et al. ${ }^{4}$ Nevertheless, the latter authors also found that $\alpha$ - and $\gamma$-tocopherol were the main ones responsible for total vitamin $\mathrm{E}$ activity in their asparagus samples. Expressing the results on a dry weight basis, the total tocopherol content $(2.1 \mathrm{mg}$ per $100 \mathrm{~g}$ ) of cultivated $A$. officinalis and wild A. acutifolius (2.78 $\mathrm{mg}$ per $100 \mathrm{~g}$ ) were higher than the one obtained herein $(0.162 \mathrm{mg}$ per $100 \mathrm{~g}) \cdot{ }^{4,27}$

3.2.3. Volatile compounds. Solid-phase micro-extraction coupled with GC-MS was used for the characterization of the volatile compounds in A. stipularis young shoots (Table 3). Thirty compounds were identified, accounting for $98.6 \%$ of the total emitted volatiles. They included alcohols, esters, aldehydes, hydrocarbons, terpenoids, apocarotenes and others, aldehydes and hydrocarbons being the main chemical classes. Aldehydes were also described as the major volatile compounds for three genotypes of A. officinalis reported by Sun et $a .^{28}$ Among aldehydes, hexanal, heptenal, octanal, benzaldehyde, nonanal and decanal were detected. The same compounds were also reported by Chin et al. ${ }^{28}$ in the volatile com-
Table 3 Volatile compounds (\% of total volatile compounds) evaluated in Asparagus stipularis Forssk. young shoots

\begin{tabular}{lcc}
\hline Volatiles & l.r.i. & Content (\%) \\
\hline Hexanal & 802 & $4.1 \pm 0.08$ \\
Isovaleric acid & 836 & $1.6 \pm 0.11$ \\
2-Methylbutanoic acid & 845 & $1.7 \pm 0.10$ \\
$p$-Xylene & 865 & $1.3 \pm 0.11$ \\
2,5-Dimethylpyrazine & 913 & $1.6 \pm 0.14$ \\
Butyrolactone & 914 & $4.6 \pm 0.06$ \\
(Z)-2-Heptenal & 961 & $1.3 \pm 0.17$ \\
Benzaldehyde & 962 & $3.4 \pm 0.09$ \\
1-Octen-3-ol & 981 & $3.4 \pm 0.011$ \\
Hexanoic acid & 987 & $6.4 \pm 0.05$ \\
Octanal & 1002 & $2.4 \pm 0.09$ \\
Limonene & 1032 & $11.5 \pm 0.01$ \\
$\gamma$-Terpinene & 1063 & $2.7 \pm 0.11$ \\
2-Acetylpyrrole & 1067 & $4.6 \pm 0.08$ \\
$n$-Undecane & 1100 & $2.5 \pm 0.07$ \\
Linalool & 1101 & $1.7 \pm 0.11$ \\
Nonanal & 1104 & $11.7 \pm 0.02$ \\
Pentylisovalerate & 1108 & $1.5 \pm 0.18$ \\
(Z)-3-Hexenyl isobutyrate & 1143 & $2.3 \pm 0.16$ \\
2-Ethylhexyl acetate & 1155 & $5.6 \pm 0.06$ \\
8-Methylnonanal & 1172 & $1.6 \pm 0.15$ \\
$\alpha$-Terpineol & 1191 & $1.8 \pm 0.14$ \\
$n$-Dodecane & 1200 & $2.7 \pm 0.06$ \\
Decanal & 1206 & $4.7 \pm 0.06$ \\
(E)-2-Decenal & 1263 & $1.6 \pm 0.27$ \\
$n$-Tridecane & 1300 & $1.5 \pm 0.20$ \\
$n$-Tetradecane & 1400 & $3.5 \pm 0.10$ \\
$\beta$-Caryophyllene & 1419 & $1.4 \pm 0.17$ \\
(E)-Geranylacetone & 1455 & $1.6 \pm 0.14$ \\
$n$-Pentadecane & 1500 & $2.2 \pm 0.17$ \\
& & $14 \pm 0.03$ \\
Monoterpene hydrocarbons & - & $3.30 \pm 0.10$ \\
Oxygenated monoterpenes & - & $1.60 \pm 0.06$ \\
Sesquiterpene hydrocarbons & - & $6.00 \pm 0.04$ \\
Apocarotenes & - & $68.1 \pm 0.002$ \\
Nitrogen derivatives & - & 98.6 \\
Non-terpene derivatives & - & \\
Total identified & & \\
& & \\
& &
\end{tabular}

1.r.i.: Linear retention index.

position of green asparagus juice. Nonanal, the major aldehyde $(11.7 \%)$ in the studied samples, has been used for different purposes, such as the improvement and monitoring of oral breath odour and the diagnosis of some human illnesses. $^{29}$

Among terpenoids, limonene showed the highest percentage in A. stipularis young shoots. It has been employed to prevent gastric diseases ${ }^{30}$ and it is also known for its antiproliferative effects. $^{31}$ As for alcohols, 1-octen-3-ol was detected. This alcohol is also known as mushroom alcohol because it is the major component of the volatiles in cultivated mushroom, and it is the dominant contributor to the characteristic mushroom flavour. ${ }^{27}$ The analysis of volatiles can be a useful tool to provide an objective guide for the analysis and improvement of the flavour characteristics of wild asparagus, as well as other crops.

3.2.4. Phenolic compounds. The phenolic profile of A. stipularis young shoots was characterized by the presence of flavonol and hydroxycinnamoyl derivatives. Thirteen main 
Table 4 Retention time (Rt), wavelengths of maximum absorption in the UV-vis region, mass spectrometric data, tentative identification and quantification of individual phenolic compounds in wild Asparagus young shoots (mg per $100 \mathrm{~g}$ of dw)

\begin{tabular}{|c|c|c|c|c|c|c|c|c|}
\hline Peak & $\begin{array}{l}\text { Rt } \\
(\min )\end{array}$ & $\begin{array}{l}\text { UV-vis } \\
\max (\mathrm{nm})\end{array}$ & $\begin{array}{l}{[\mathrm{M}-\mathrm{H}]} \\
(m / z)\end{array}$ & $\operatorname{MS}^{2}(m / z)$ & Compound & Infusion & $\begin{array}{l}\text { Hydroalcoholic } \\
\text { extract }\end{array}$ & $p$-Value \\
\hline 1 & 7.4 & 331 & 355 & $193,174,134$ & Feruloylhexoside & $1.36 \pm 0.05$ & $1.47 \pm 0.07$ & $>0.05$ \\
\hline 4 & 14.3 & 254,353 & 769 & $314,299,271$ & Isorhamnetin-O-dideoxyhexosylhexoside & $3.02 \pm 0.11$ & $2.66 \pm 0.33$ & $>0.05$ \\
\hline 5 & 15.0 & 324 & 267 & $193,175,160,134$ & Feruloyl glycerol & $1.20 \pm 0.04$ & $1.10 \pm 0.16$ & $>0.05$ \\
\hline 6 & 15.4 & 266,350 & 609 & 301 & Quercetin-3-O-rutinoside & $1.02 \pm 0.08$ & $1.10 \pm 0.06$ & $>0.05$ \\
\hline 9 & 20.1 & 324 & 459 & 241,139 & Unknown hydroxycinnamoyl derivative & $1.02 \pm 0.08$ & $0.98 \pm 0.11$ & $>0.05$ \\
\hline 10 & 29.3 & 315 & 413 & $193,163,145,134$ & Coumaroylferuloyl glycerol I & $3.03 \pm 0.12$ & $3.86 \pm 0.43$ & $<0.05$ \\
\hline 11 & 29.8 & 325 & 443 & $193,175,161,135$ & Diferuloyl glycerol I & $5.38 \pm 0.01$ & $7.07 \pm 0.80$ & $<0.05$ \\
\hline 12 & 30.1 & 313 & 413 & $193,161,145,134$ & Coumaroylferuloyl glycerol II & $0.22 \pm 0.03$ & $1.05 \pm 0.12$ & $<0.05$ \\
\hline \multirow[t]{3}{*}{13} & 30.6 & 324 & 443 & $193,175,160,134$ & Diferuloyl glycerol II & $0.55 \pm 0.01^{\mathrm{a}}$ & $1.95 \pm 0.10^{\mathrm{b}}$ & $<0.05$ \\
\hline & & & & & Total flavonoids & $11.03 \pm 0.42$ & $10.86 \pm 0.65$ & $>0.05$ \\
\hline & & & & & Total phenolic acid derivatives & $14.10 \pm 0.14$ & $18.69 \pm 1.05$ & $<0.05$ \\
\hline
\end{tabular}

$p<0.05$ means significant differences.

compounds were detected, and the peak characteristics (UV absorption and mass spectra), tentative identities and quantitative results are presented in Table 4. Five peaks were associated with flavonol glycosides according to their characteristic UV spectra that were identified as quercetin, kaempferol, and isorhamnetin derivatives based on their mass spectral data. The types of sugar substituents were deduced from the mass difference between the $\mathrm{m} / \mathrm{z}$ values of the pseudomolecular ions and the aglycones, i.e., 454 Da (peaks 2, 3 and 4) and $308 \mathrm{Da}$ (peaks 6 and 8), coherent with combinations of deoxyhexosyl (146 Da) and hexosyl moieties (162 Da). In all cases, sugar substituents were assumed to be in the form of di- or trisaccharides; otherwise, fragments corresponding to the alternative loss of the distinct sugars should have been observed. Thus, compounds 6 and 8 would contain one hexosyl and one deoxyhexosyl residue, while compounds 2, 3 and 4 have one hexosyl and two deoxyhexosyls. Peaks 6 and 8 were tentatively assigned to quercetin-3-O-rutinoside and isorhamnetin-3-O-rutinoside, owing to their previous identification in different species of Asparagus. ${ }^{8,32}$ Based on this assumption, peaks 2,3 and 4 might be supposed to correspond to the rhamnosyl-rutinosides of quercetin, kaempferol and isorhamnetin, respectively. However, since no definite conclusion about the nature and location of the sugars can be obtained from the mass spectral data, they were just assigned to $O$-dideoxyhexosyl-hexosides. Two compounds possessing $[\mathrm{m}-\mathrm{H}]^{-}$ions at $m / z 755$ and 769 , as here obtained for peaks 2 and 4, were reported in green asparagus by Fuentes-Alventosa et al., ${ }^{33}$ although they were just designed as quercetin and isorhamnetin triglycosides.

The remaining eight peaks were associated with hydroxycinnamoyl derivatives, according to their UV spectra showing characteristic shapes with maximum wavelengths of absorption at $320-330 \mathrm{~nm}$. Among them, peaks 1, 5 and 10-13 were assigned to different feruloyl derivatives based on their mass features as previously described in A. officinalis. ${ }^{33}$ Compounds
10 and 12 showed the same pseudomolecular ion $\left([\mathrm{m}-\mathrm{H}]^{-}\right.$at $\mathrm{m} / \mathrm{z} 413$ ) and this similarly happened with compounds 11 and $13\left([\mathrm{~m}-\mathrm{H}]^{-}\right.$at $\left.m / z 443\right)$, which can be explained by the substitution of the feruloyl/coumaroyl residues on any of the three hydroxyl groups of glycerol. Actually, the presence of 1,2-Odiferuloyl glycerol and 1,3-O-diferuloyl glycerol was reported in A. officinalis, ${ }^{33,34}$ which could correspond to the peaks 11 and 13 detected herein. No conclusions on the identity of peaks 7 and 9 could be obtained, which remained as unknown hydroxycinnamoyl derivatives.

\subsection{Bioactive properties}

3.3.1. Antioxidant activity. The antioxidant activity of A. stipularis young shoot extracts was evaluated using four different methods: DPPH and ABTS radical scavenging activity, ferric reducing power assay and TBARS determination in brain homogenates. As it can be seen in Table 5, for all the antioxidant activity assays, the hydroalcoholic extract gave the lowest $\mathrm{EC}_{50}$ value. ABTS, DPPH and ferric reducing power assays were applied to evaluate the total antioxidant capacity, obtaining $\mathrm{EC}_{50}$ values of $3.86,2.20$ and $1.19 \mathrm{mg} \mathrm{mL}^{-1}$ for the hydroalcoholic extract, respectively. As for the infusion, ABTS, DPPH and ferric reducing power assays gave values of 7.41, 6.16 and $3.70 \mathrm{mg} \mathrm{mL}^{-1}$, respectively. The TBARS assay was used for the evaluation of lipid peroxidation. The values of 3.19 and $0.86 \mathrm{mg} \mathrm{ml}^{-1}$ were obtained for infusion and hydroalcoholic extracts, respectively. The higher antioxidant activity of the hydroalcoholic extract was probably related to the higher content of total phenolic compounds found in this extract, compared to the infusion (Table 5). According to Fuentes-Alventosa et al. ${ }^{32}$ the correlation between phenolic compounds and the antioxidant activity of asparagus has been previously reported. Comparing the results with other wild Mediterranean species, the A. stipularis hydroalcoholic extract has greater antioxidant activity measured by DPPH and redu- 
Table 5 Antioxidant $\left(\mathrm{EC}_{50}\right.$ values, $\mathrm{mg} \mathrm{mL}^{-1}$ ) and cytotoxic activities $\left(\mathrm{Gl}_{50}\right.$ values $\left.\mu \mathrm{g} \mathrm{mL}^{-1}\right)$ of $A$. stipularis young shoots

\begin{tabular}{llll}
\hline & Infusion & $\begin{array}{l}\text { Hydroalcoholic } \\
\text { extract }\end{array}$ & $p$-Value \\
\hline DPPH scavenging activity & $6.16 \pm 0.003^{\mathrm{b}}$ & $2.206 \pm 0.14^{\mathrm{a}}$ & $<0.05$ \\
ABTS scavenging activity & $7.41 \pm 0.051^{\mathrm{b}}$ & $3.86 \pm 0.07^{\mathrm{a}}$ & $<0.05$ \\
Reducing power assay & $3.70 \pm 0.019^{\mathrm{b}}$ & $1.19 \pm 0.023^{\mathrm{a}}$ & $<0.05$ \\
TBARS inhibition assay & $3.19 \pm 0.17^{\mathrm{b}}$ & $0.86 \pm 0.011^{\mathrm{a}}$ & $>0.05$ \\
& & & \\
$\begin{array}{l}\text { MCF-7 (breast carcinoma) } \\
\text { NCI-H460 (non-small }\end{array}$ & $>400$ & $298.63 \pm 4.51$ & - \\
$\begin{array}{l}\text { cell lung cancer) } \\
\text { HeLa (cervical carcinoma) }\end{array}$ & $>400$ & $244.26 \pm 8.82$ & - \\
$\begin{array}{l}\text { HepG2 (hepatocellular } \\
\text { carcinoma) }\end{array}$ & $>400$ & $208.24 \pm 6.02$ & - \\
& & $200.77 \pm 3.51$ & - \\
PLP2 & $>400$ & $>400$ &
\end{tabular}

$\mathrm{EC}_{50}$ : Extract concentration corresponds to $50 \%$ of antioxidant activity or 0.5 of absorbance in the reducing power assay. The $\mathrm{GI}_{50}$ values correspond to the sample concentration achieving $50 \%$ of growth inhibition in human tumour cell lines or in liver primary culture PLP2. $p<0.05$ means significant differences.

cing power assays than the Spanish samples of Asparagus acutifolius, Bryonia dioica, Scolymus hispanicus L., Silybum marianum (L.) and Tamus communis L. previously analyzed. ${ }^{4}$ As for infusion, the DPPH and FRAP values of A. stipularis were higher than those reported for the Portuguese Foeniculum vulgare Mill. and Spanish Scolymus hispanicus L. samples. ${ }^{2,4}$

Regarding the DNA nicking assay, the effect of A. stipularis extracts was evaluated qualitatively on supercoiled pGEM®Tplasmid DNA. According to Abbas et al., ${ }^{35}$ hydroxyl radicals generated by the Fenton reaction are responsible for oxidatively induced breaks in the DNA strands. The obtained electropherograms of the current assay are shown in Fig. 1. The direction of migration is from the lower to upper part of the electropherograms. The faster moving band corresponds to the supercoiled circular DNA and the slower moving band represents the open circular DNA following treatment with Fenton's reagent. The control (lane 2) showed the absence of specific band in the treated DNA, which indicates DNA damage. The addition of the asparagus young shoot infusion (lane 3) and hydroalcoholic extract (lane 4) to the reaction mixture decreased the DNA strand scission and retained the supercoiled form, thus effectively protecting the DNA. To the best of our knowledge, this is the first report on the DNA protecting ability of $A$. stipularis extracts.

3.3.2. Antiproliferative activity. The antiproliferative properties of the asparagus young shoot extracts were evaluated in vitro by the estimation of cell growth effects on four human tumour cell lines (MCF-7, HCT-15, HeLa and HepG2). The results are shown in Table 5 . All the cell lines were inhibited in a dose-dependent manner by the hydroalcoholic extract. The lowest $\mathrm{GI}_{50}$ values were obtained for HepG2 and HeLa (200.77 and $208.24 \mu \mathrm{g} \mathrm{mL} \mathrm{m}^{-1}$, respectively). A possible explanation for this observation could be the presence of steroidal saponins in the extract, which have been reported to have antitumor

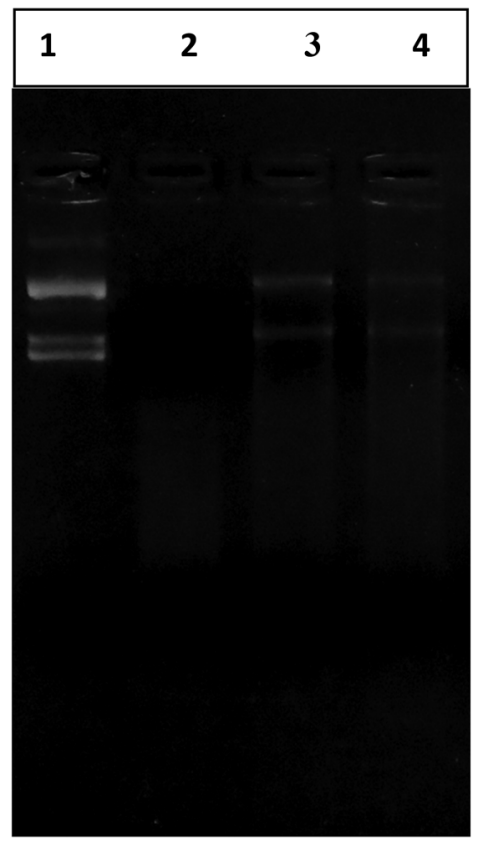

Fig. 1 Inhibitory effects of $A$. stipularis young shoot extracts on DNA nicking caused by hydroxyl radicals. Lane 1: native pGEM®-Tplasmid DNA; lane 2: Fenton's reagent + DNA; lane 3: Fenton's reagent + DNA + infusion ( $2 \mathrm{mg} \mathrm{ml}^{-1}$ ); lane 4: Fenton's reagent + DNA + hydroalcoholic extract $\left(2 \mathrm{mg} \mathrm{mL}^{-1}\right)$.

activity. ${ }^{35}$ Asparanin A isolated from A. officinalis has been found to induce cell cycle arrest in human hepatocellular carcinoma HepG2 cells. $^{36}$ Anti-cancer properties against HL-60 (human promyelocytic leukemia) and Hep G2 cells were also demonstrated for ursolic acid isolated from A. officinalis young shoots. ${ }^{37}$ The infusion extract had no antitumor effects at the maximal concentration used $\left(400 \mu \mathrm{g} \mathrm{mL}{ }^{-1}\right)$. Despite the observed cytotoxic activity on human tumour cell lines, none of the A. stipularis preparations showed hepatotoxicity in the porcine liver primary cell culture (non-tumour cells; PLP2).

This study is a contribution to the overall knowledge on the phytochemistry and biopotential of A. stipularis young shoots. According to the obtained results, A. stipularis young shoots are a good source of essential and non-essential nutrients. The hydroalcoholic extract of the young shoots exhibited appreciable antioxidant and antiproliferative activities compared to the aqueous extract. Both extracts were found to be nonhepatotoxic against PLP2 cells up to the maximal tested concentration $\left(400 \mu \mathrm{g} \mathrm{mL} \mathrm{m}^{-1}\right)$. The phenolic profile of A. stipularis young shoots was characterized by the presence of flavonol and hydroxycinnamoyl derivatives as the main compounds.

In conclusion, A. stipularis might be an interesting candidate to improve and recover wild plant consumption, including it young shoots as part of the Mediterranean diet in the socalled modern diets rich in antioxidant and biofunctional foods and food product, as well as for the development of new antioxidant and cancer chemopreventive dietary supplements or nutraceuticals. 


\section{Conflicts of interest}

The authors declare that have no conflicts of interest.

\section{Acknowledgements}

Thanks are due to the ALIMNOVA research group (project UCM-252/2017), the Foundation for Science and Technology (FCT, Portugal) and the FEDER Program PT2020 for financial support to CIMO (UID/AGR/00690/2013) and R. Calhelha, and to A. Fernandes (SFRH/BPD/114753/2016), as well as to the Spanish MINECO for financial support to GIP-USAL (Project AGL2015-64522-C2-2-R).

\section{References}

1 L. Ferrara, R. Dosi, A. Di Maro, V. Guida, G. Cefarelli, S. Pacifico, C. Mastellone, A. Fiorentino, A. Rosati and A. Parente, Nutritional values, metabolic profile and radical scavenging capacities of wild asparagus (A. acutifolius, L.), J. Food Compos. Anal, 2011, 24, 326-333.

2 D. Martins, L. Barros, A. M. Carvalho and I. C. F. R. Ferreira, Nutritional and in vitro antioxidant properties of edible wild greens in Iberian Peninsula traditional diet, Food Chem., 2011, 125, 488-494.

3 P. Morales, I. C. F. R. Ferreira, A. M. Carvalho, M. C. Sanchez-Mata, M. Cámara and J. Tardio, Fatty acids profiles of some Spanish wild vegetables, Food Sci. Technol. Int. , 2012, 18, 281-290.

4 P. Morales, A. M. Carvalho, M. C. Sánchez-Mata, M. Cámara, M. Molina and I. C. F. R. Ferreira, Tocopherol composition and antioxidant activity of Spanish wild vegetables, Genet. Resour. Crop Evol., 2012, 59, 851-863.

5 C. Pereira, L. Barros, A. M. Carvalho and I. C. F. R. Ferreira, Use of UFLC-PDAfortheAnalysisofOrganicAcidsinThirtyFiveSpeciesofFoodandMedicinal Plants, Food Anal. Methods, 2012, 6, 1337-1344.

6 A. Di Maro, S. Pacifico, A. Fiorentino, S. Galasso, M. L. Gallicchio, V. Guida, V. Severino, P. Monaco and A. Parente, Raviscanina wild asparagus (Asparagus acutifolius L.): A nutritionally valuable crop with antioxidant and antiproliferative properties, Food Res. Int., 2013, 53, 180188.

7 J. Tardío, M. Sánchez-Mata, M. Ramón, M. Molina, P. García-Herrera, P. Morales, C. Díez-Marqués, V. Fernández-Ruiz, M. Cámara, M. Pardo-de-Santayana, M. C. Matallana-González, B. M. Ruiz-Rodríguez, D. Sánchez-Mata, M. E. Torija-Isasa, J. L. Guil-Guerrero and N. Boussalah, Ethnobotanical and Food Composition Monographs of Selected Mediterranean Wild Edible Plants, Mediterranean Wild Edible Plants, Springer Science+Business Media New York, 2016.

8 L. Barros, M. Dueñas, I. C. F. R. Ferreira, A. M. Carvalho and C. Santos-Buelga, Use of HPLC-DAD-ESI/MS to profile phenolic compounds in edible wild greens from Portugal, Food Chem., 2011, 127, 169-173.

9 E. Pinho, I. C. F. R. Ferreira, L. Barros, A. M. Carvalho, G. Soares and M. Henriques, Antibacterial potential of northeastern Portugal wild plant extracts and respective phenolic compounds, BioMed Res. Int., 2014, 2014, 814590.

10 M. Wang, Y. Tadmor, Q. L. Wu, C. K. ChIN, S. A. Garrison and J. E. Simon, Quantification of Protodioscin and Rutin in Asparagus Shoots by LC/MS and HPLC Methods, J. Agric. Food Chem., 2003, 51, 6132-6136.

11 Z. Sui, C. Qi, Y. Huang, S. Ma, X. Wang, G. Le and J. Sun, Aqueous extracts from asparagus stems prevent memory impairments in scopolamine-treated mice, Food Funct., 2017, 8, 1460-1467.

12 K. Ulukapi, A. G. Nasircilar, A. N. Onus and I. Baktir, In vitro propagation and determination of the nutrient content of naturally grown Asparagus stipularis, Forssk, Arch. Biol. Sci., 2014, 66, 1333-1338.

13 H. R. El-Seedi, R. El-Shabasy, H. Sakr, M. Zayed, A. M. A. ElSaid, K. M. H. Helmy, A. H. M. Gaara, Z. Turki, M. Azeem, A. M. Ahmed, L. Boulos, A. K. Borg-Karlson and U. Göransson, Anti-schistosomiasis triterpene glycoside from the Egyptian medicinal plant Asparagus stipularis, Rev. Bras. Farmacogn., 2011, 22, 314-318.

14 AOAC, Official methods of analysis, Association of Official Analytical Chemists Gaithersburg, Maryland, 18th edn, 2005.

15 B. Mechri, M. Tekaya, H. Cheheb and M. Hammami, Determination of mannitol sorbitol and myo-inositol in olive tree roots and rhizospheric soil by gas chromatography and effect of severe drought conditions on their profiles, J. Chromatogr. Sci., 2015, 53, 1-7.

16 P. García-Herrera, P. Morales, V. Fernández-Ruiz, M. C. Sánchez-Mata, M. Cámara, A. M. Carvalho, I. C. F. R. Ferreira, M. Pardo-de-Santayana, M. Molina and J. Tardio, Nutrients, phytochemicals and antioxidant activity in wild populations of Allium ampeloprasum L., a valuable underutilized vegetable, Food Res. Int., 2014, 62, 272-279.

17 M. Dhibi, B. Mechri, I. Cheraif and M. Hammami, TransFatty acid isomers in two sesame (Sesamum indicum L.) seed byproducts under processing, J. Agric. Food Chem., 2010, 58, 12210-12215.

18 M. I. Dias, L. Barros, M. Dueñas and I. C. F. R. Ferreira, Chemical composition of wild and commercial Achillea millefoliumL. and bioactivity of the methanolic extract, infusion and decoction, Food Chem., 2013, 141, 4152-4160.

19 A. Jelled, R. Ben Hassine, A. Thouri, G. Flamini, H. Chahdoura, A. El Arem, J. Ben Lamine, A. Kacem, Z. Haouas, H. Ben Cheikh and L. Achour, Immature mulberry fruits richness of promising constituents in contrast with mature ones: A comparative study among three Tunisian species, Ind. Crops Prod., 2016, 95, 434-443.

$20 \mathrm{H}$. Ohkawa, N. Ohishi and K. Yagi, Assay for lipid peroxides in animal tissues by thiobarbituric acid reaction, Anal. Biochem., 1979, 95, 351-358. 
21 J. Lee, H. Kim, J. Kim and Y. Jang, Antioxidant property of an ethanol extract of the stem of Opuntia ficus-indica var. Saboten, J. Agric. Food Chem., 2002, 50, 6490-6496.

22 E. Lecumberri, L. Goya, R. Mateos, M. Alia, S. Ramos, M. Izquierdo-Pulido and L. Bravo, A diet rich in dietary fiber from cocoa improves lipid profile and reduces malondialdehyde in hypercholesterolemic rats, J. Nutr., 2007, 23, 332-341.

23 G. Qiao-Juan, Y. Hai-Ying and G. Gui-Zhen, Determination of trace elements in Asparagus (Asparagus officinalis L.) by fame atomic absorption spectrometry (FAAS), J. Med. Plants Res., 2010, 1, 24-26.

24 D. J. Makus, Response in green and white Asparagus to supplemental nitrogen and harvest date, J. Hortic. Sci., 1995, 30, 55-58.

25 P. García-Herrera, Plantas silvestres de consumo tradicional. Caracterización de suvalornutricional y estimación de suactividadantifúngica, PhD Thesis, Universidad Complutense de Madrid (Spain), 2014.

26 M. A. French, K. Sundram and M. T. Clandinin, Cholesterolaemic effect of palmitic acid in relation to other dietary fatty acids, Asia Pac. J. Clin. Nutr., 2002, 11, 401-407.

27 S. W. Souci, W. Fachmann and G. Kraut, Food composition and nutrition tables, Taylor \& Francis/CRC Press Book, USA, 7th revised and completed edn, 2008.

28 R. Sun, Y. Wang, C. K. Chin and S. A. Garrison, Volatile compounds in Asparagus officinalis, L., Acta Hortic., 2002, 589, 257-266.

29 X. Chen, W. Qin, L. Ma, F. Xu, P. Jin and Y. Zheng, Effect of high pressure processing and thermal treatment on physicochemical parameters, antioxidant activity and volatile compounds of green asparagus juice, LWT - Food Sci Technol, 2015, 62, 927-933.
30 T. Itoh, T. Nakashima, T. Akamatsu, N. Izu and W. Shin, Nonanal gas sensing properties of platinum, palladium, and gold-loaded tin oxide VOCs sensors, Sens. Actuators, B, 2013, 187, 135-141.

31 J. Sun, D-Limonene: safety and clinical applications, Altern. Med. Rev., 2007, 12, 259-265.

32 P. L. Crowell, S. Lin, E. Vedejs and M. N. Gould, Identification of metabolites of the antitumor agent d-limonene capable of inhibiting protein isoprenylationand cell growth, Cancer Chemother. Pharmacol., 1992, 31, 205-212.

33 J. M. Fuentes-Alventosa, S. Jaramillo, G. RodriguezGutierrez, P. Cermeno, J. A. Espejo, A. Jimenez-Araujo, R. Guillen-Bejarano, J. Fernandez-Bolanos and R. Rodriguez-Arcos, Flavonoid profile of green asparagus genotypes, J. Agric. Food Chem., 2008, 56, 6977-6984.

34 D. S. Jang, M. Cuendet, H. H. S. Fong, J. M. Pezzuto and A. D. Kinghorn, Constituents of Asparagus officinalis evaluated for inhibitory activity against cyclooxygenase-2, J. Agric. Food Chem., 2004, 52, 2218-2222.

35 S. R. Abbas, D. M. Sabir, S. D. Ahmad, A. A. Boligon and M. A. Athayde, Phenolic profile, antioxidant potential and DNA damage protecting activity of sugarcane (Saccharum officinarum), Food Chem., 2014, 147, 10-16.

36 Y. Shao, C. K. Chin, C. T. Ho, W. Ma, S. A. Garrison and M. T. Huang, Anti-tumor activity of the crude saponins obtained from asparagus, Cancer Lett., 1996, 104, 31-36.

37 W. Liu, X. F. Huang, Q. Qui, Q. S. Dai, L. Yang, F. F. Nie, N. Lu, D. D. Gong, L. Y. Kong and Q. Guo, Asparanin A induces $\mathrm{G}(2) / \mathrm{M}$ cell cycle arrest and apoptosis in human hepatocellular carcinoma HepG2 cells, Biochem. Biophys. Res. Commun., 2009, 381, 700-705. 